NBER WORKING PAPER SERIES

\title{
ENROLLMENT IN MEDICARE ADVANTAGE PLANS IN MIAMI-DADE COUNTY: EVIDENCE OF STATUS QUO BIAS?
}

\author{
Anna D. Sinaiko \\ Christopher C. Afendulis \\ Richard G. Frank \\ Working Paper 19639 \\ http://www.nber.org/papers/w19639 \\ NATIONAL BUREAU OF ECONOMIC RESEARCH \\ 1050 Massachusetts Avenue \\ Cambridge, MA 02138 \\ November 2013
}

The authors gratefully acknowledge funding from the National Institute of Aging through P01 AG032952, The Role of Private Plans in Medicare. Portions of these results were presented at the Academy Health Annual Research Meeting held in Baltimore, MD in June 2013. An abbreviated version of this paper has been accepted for publication by Inquiry. The views expressed herein are those of the authors and do not necessarily reflect the views of the National Bureau of Economic Research.

NBER working papers are circulated for discussion and comment purposes. They have not been peerreviewed or been subject to the review by the NBER Board of Directors that accompanies official NBER publications.

(C) 2013 by Anna D. Sinaiko, Christopher C. Afendulis, and Richard G. Frank. All rights reserved. Short sections of text, not to exceed two paragraphs, may be quoted without explicit permission provided that full credit, including $\odot$ notice, is given to the source. 
Enrollment in Medicare Advantage Plans in Miami-Dade County: Evidence of Status Quo Bias?

Anna D. Sinaiko, Christopher C. Afendulis, and Richard G. Frank

NBER Working Paper No. 19639

November 2013

JEL No. I13

\begin{abstract}
Evidence from behavioral economics reveals that decision-making in health care settings can be affected by circumstances and choice architecture. This paper conducts an analysis of choice of private Medicare plans (Medicare Advantage plans) in Miami-Dade County. We provide a detailed description of the choice of MA plans available in Miami over much of the program's history and the composition of Medicare beneficiaries in Miami over the 2000s. Our analysis suggests that first becoming eligible for Medicare is the key transition point for MA, and that there is significant status quo bias in the MA market. This consumer behavior has important implications for policy that regulates the MA market.

\author{
Anna D. Sinaiko \\ Department of Health Policy and Management \\ Harvard School of Public Health \\ 677 Huntington Avenue, Rm 433 \\ Boston, MA 02115 \\ asinaiko@hsph.harvard.edu \\ Christopher C. Afendulis \\ Harvard Medical School \\ 180 Longwood Avenue \\ Boston, MA 02115 \\ afendulis@ @cp.med.harvard.edu
}

एسIسIRichard G. Frank

Department of Health Care Policy
\end{abstract}




\section{Introduction}

The Medicare program that provides health insurance to older Americans, offers beneficiaries a choice of health plans. Beneficiaries can enroll in Traditional Medicare (TM), which offers fee-for-service health insurance administered by the government, or they can participate in the Medicare Advantage program (MA), also known as Part C of Medicare, where beneficiaries select a private health plan offered by a health insurance company. ${ }^{1} \mathrm{MA}$ plans provide benefits that are at least actuarially equivalent to TM and most are managed care plans.

Private plans were introduced into the Medicare program in 1985 with the dual goals of offering beneficiaries a choice for their health insurance plan and of stimulating what was thought to be efficient provision of health care stemming from competition and managing care under a budget (McGuire et al 2011). The enrollment patterns of beneficiaries affect whether the MA program is able to achieve these goals. In particular, when consumers are efficient decision-makers who recognize and take advantage of a "better deal" when it is offered by an MA plan, there is an incentive for plans to compete on price and quality. Yet, research on consumer choice of health insurance plans finds that consumers' enrollment decisions are often affected by factors unrelated to the cost and quality of the health plan, such as the decision context in which they choose a plan, and that this can result in consumers making poor choices. In Medicare Advantage health insurance products are complex, many beneficiaries of the program are frail, and only crude measures of plan performance exist. These market features can increase the likelihood of errors in choice, for example, by a beneficiary failing to enroll in the Medicare option (either an MA plan or TM) that best meets their needs. ${ }^{2}$

\footnotetext{
${ }^{1}$ Throughout the program's history Part C has had several different names. Medicare Advantage dates to the Medicare Modernization and Improvement Act of 2003.

${ }^{2}$ As a practical matter, it is difficult to identify errors in choice.
} 
Medicare Advantage regulations and policy have varied over the history of the program, as has beneficiary enrollment. In the most recent decade, the enactment of the Medicare Modernization and Improvement Act of 2003 (MMA) changed MA payment policy so as to encourage growth in the MA program, both through an increase in number of private plans offered to beneficiaries and an increase in the number of beneficiaries who enroll in MA. The MMA's efforts to spur growth in MA were primarily through large, across-the-board increases in plan payments - that came at a high cost to the Federal government. Since 2003, the number of plans available to beneficiaries steadily increased and plans began to offer richer benefit packages than TM in the form of reduced out-of-pocket costs and extra benefits (MedPAC 2007; MedPAC 2009a). Nationally, MA enrollment increased dramatically, from 13\% in 2003 to 27\% in 2012 (Gold et al 2012). In general, Medicare beneficiaries who enroll in MA accept having their care managed and the fact that they face some restrictions on physician networks in exchange for more comprehensive coverage. The exceptions are the Private Fee-ForService (PFFS) plans, a set of MA options that during our study period did not impose restrictions on physician networks. PFFS plans have been available since the mid-2000s. Previous research on demand for MA, which we describe below, has focused on the characteristics of beneficiaries enrolled in MA plans. Less attention has been given to understanding the extent to which take-up of MA is consistent with efficient consumer decision making.

In this paper, we examine the choices of MA plans available to Medicare beneficiaries over time and answer two sets of questions about the patterns of MA enrollment within one market in order to enhance our understanding of demand for MA plans. First, what are the patterns of demand for and enrollment into MA over the mid-2000s, when it becomes arguably a "better deal" for consumers? Second, what characteristics of individuals and their circumstances are associated with choice of MA? Is there evidence of status quo bias in demand for MA plans? 
The study focuses on Miami-Dade County, Florida, a setting that we select for two main reasons. First, Miami-Dade has a large elderly population with ethnic and socioeconomic diversity. This variation provides a good setting to examine the role of beneficiary characteristics on MA enrollment. Second, Miami-Dade County has consistently offered beneficiaries an attractive alternative set of plans to TM, and MA penetration has been high. MA plan choices in Miami have become even richer over the past decade. Thus, for payers and policymakers who seek to understand the potential for MA to create an efficient marketplace, analysis of the MA experience in Miami-Dade is potentially very informative.

The remainder of the paper is organized as follows. Section 2 reviews the relevant literature on health insurance choice and decision-making. Section 3 describes and discusses the MA market in Miami-Dade. Section 4 describes the data and methods. Section 5 presents results, where we find evidence that certain observable sources of frictions explain why subsets of Medicare beneficiaries select or switch into MA when others do not. We conclude in Section 6.

\section{Relevant Literature}

Existing literature documents the experience of MA in terms of plan payments, the number and types of MA plans offered, and the enrollment of beneficiaries in MA over time. ${ }^{3}$ Recent studies identify MA enrollees as more likely to be racial/ethnic minorities, have lower income, and have less education than enrollees in TM (Norwalk, Testimony March 21, 2007; McWilliams et al 2011). Particularly relevant to this study is the literature that examines the

\footnotetext{
${ }^{3}$ Details on MA performance, in terms of program enrollment, spending, and quality are published
} annually by the Medicare Payment Advisory Commission (see for example MedPAC 2011), and in several reports available through The Commonwealth Fund (www.cmwf.org) and the Kaiser Family Foundation (www.kff.org). (Gold 2009) and (Gold et al 2012) report on recent years of the MA program. McGuire et al (2011) provides a review of the program's economic history. 
quality of consumer decision-making. Two types of problems have been identified in demand behavior (a) poor information and (b) seemingly irrational behavior. A large literature has treated information problems in health care. During the first two decades of the MA program, when MA plan payments were adjusted for demographic factors but not enrollee health, thereby creating strong incentives for plans to avoid enrolling sicker beneficiaries, MA plans experienced favorable selection in comparison to TM by enrolling beneficiaries who were lower cost than those in TM (Physician Payment Review Commission 1996; Medicare Payment Advisory Commission 2000; Riley and Zarabozo 2006-2007). As of 2006, the introduction of riskadjusted payments that account for both an enrollee's demographics and clinical diagnoses has been found to have reduced favorable selection into MA (Newhouse et al 2012; McWilliams et al 2012).

In this paper we focus on factors that lead to seemingly irrational choice, and in particular draw on literature that health insurance choices are prone to frictions that lead to status quo bias, i.e., the tendency for people to stay with their current health plan rather than switch plans, which can inhibit optimal choices. In their seminal paper, Samuelson and Zeckhauser (1988) discuss several factors that may contribute to status quo bias, some of which, such as the presence of search and transition costs, uncertainty about alternate options, and the decision to realize investments made in current choices (i.e. sunk costs), are consistent with rational choice because they make change costly. The authors also find evidence suggestive that status quo bias can result from psychologically based deviations from the rational choice model, due to an endowment effect where a possession takes on an exaggerated value relative to what people would pay for it for the first time in the market (Tversky and Kahneman 1991) and regret avoidance, where people do not switch plans so as to avoid learning that their initial choice was a bad one (Kahneman and Tversky 1982). Other studies report evidence of status quo bias in private health insurance markets (Strombom et al. 2002), including one instance where the consequence of this inertia was for consumers to 
remain enrolled in a plan that was unequivocally worse than another available option for all enrollees (i.e. a dominated plan) (Sinaiko and Hirth 2011).

A substantial theoretical and empirical literature finds that consumers are frequently susceptible to defaults, often as a result of inertia, and that these passive decisions are not reflective of conscious or meaningful choices but instead result from other forces, like procrastination (Beshears et al 2008). This literature on passive choice and susceptibility towards defaults is largely focused on financial planning and savings decisions but has also been applied to a range of other issues ranging from organ donation to product warranties (see for example, Goldstein et al 2008; Madrian and Shea 2001), where there is significant uncertainty, high-stakes, and anxiety. Uncertainty, high-stakes and anxiety are three features often present in decisions to enroll in or switch among health plans, and thus different outcomes from decisions made in circumstances of passive versus active choice are likely to be observed in the Medicare program as well.

Complexity in the decision context can arise both due to difficult choices and an increasing number of choices. This latter circumstance, termed "choice overload" has been shown to exacerbate status quo bias, as complexity in the decision context leads individuals to avoid making a choice, and is inconsistent with standard economic models of demand (Baicker et al 2012). Frank and Lamiraud (2009) evaluate patterns of health plan choice in Switzerland, and find a negative relationship between the number of health plan choices available and whether a consumer decides to switch plans. Similar patterns have been observed with consumer choice of other goods, such as mutual funds (Kempf and Ruenzi 2006).

It is reasonable to expect similar or even enhanced frictions in the Medicare program, because beneficiaries face diminished decision-making and cognitive capabilities due to age and health status (Hanoch and Rice 2006), where the number of MA plans and Part D prescription drug plans is high, and where most Medicare beneficiaries need not make an active choice about coverage since they are already enrolled in an MA plan or TM so their default 
option is to do nothing. Only new Medicare beneficiaries, through the process of enrolling in Medicare, must make an active choice.

A few papers examine "mistakes" in plan choices among Medicare beneficiaries, where beneficiaries are enrolled in plans that appear less optimal than other plans. McWilliams et al (2011) find that beneficiaries with reduced cognitive function were less likely to enroll in MA (versus TM), even in instances of increasing plan generosity. These authors also find evidence consistent with choice overload, showing that while rates of enrollment in MA increased as beneficiaries faced increasing numbers of plan choices up to 15 plans, they were unchanged for choice sets including more than 15 plans.

Evidence that Medicare beneficiaries have difficulty selecting the plan that is best for them has been found in the context of Medicare Part D plans (which provide stand-alone prescription drug coverage) and where, on average in the late 2000s, beneficiaries could choose from among more than 50 Part D plans (Neuman and Cubanski, 2009). Abaluck and Gruber (2011) studied choice among Part D plans during this period and found that the vast majority of beneficiaries selected a suboptimal Part D plan, defined as plans that have higher expected out-of-pocket costs for the enrollee than another plan that offers an equivalent level of risk protection. They also present evidence that beneficiaries over-weighted information about plan premium (relative to all out-of-pocket costs) when making their Part D plan selection.

However, there is no evidence in the literature of status quo bias in Medicare beneficiary plan choices. We now turn to describe the market for MA plans in Miami-Dade County and lay out the context for our analysis of patterns of demand for MA plans.

\section{Medicare Advantage in Miami-Dade County}

Over the course of the MA program's history, the MA market in Miami-Dade County has been one of the most robust in the United States. Hurley et al (2003) analyzed data from the Community Tracking Survey, a longitudinal project conducting in-depth case studies in twelve 
nationally representative urban markets, including Miami-Dade County. As early as 1996, the authors characterized Miami-Dade as a Medicare managed care "high penetration" area, reporting one of the highest numbers of MA plans offered to beneficiaries (9 plans), and a high rate of beneficiary penetration in MA plans (37\%). The authors attribute this finding in large part to Medicare plan payment rates that were significantly higher in Miami-Dade county than the national average, and plan competition for enrollment using generous benefit packages and large networks (Ginsburg et al 1997). At that time, the only type of risk-bearing MA plan allowed to be offered was a Health Maintenance Organization (HMO).

Over the next five years, MA plans began to withdraw from almost all other markets in the country due to decreases in plan payments imposed by the Balanced Budget Act of 1997. The total number of MA plan contracts in the United States decreased from a high of 346 in 1998 to 180 in 2001, while the percent of Medicare beneficiaries enrolled in MA dropped from $16 \%$ to $12 \%(\mathrm{CMS})$. For the most part, the MA market in Miami-Dade did not experience the same contraction. During the same time frame the number of plans available in Miami-Dade held steady at 9-10 plans and by 2000, and MA penetration in Miami-Dade county increased, from 43\% in 1998 to 46\% in 2000 (Hurley et al 2003). Things began to change in 2001 with the beginnings of erosion in the generosity of MA plan benefits, including reduced pharmacy benefits and some higher co-payments (Mays et al 2001). These effects were not to be longlived.

The enactment of the Medicare Modernization and Improvement Act (MMA) in 2003 dramatically increased MA plan payments and led to significant changes in the number and types of plans available to beneficiaries in MA. Although it was the BBA that authorized new types of private plans within MA, including preferred-provider organizations (PPOs), providersponsored organizations (PSOs), and private fee-for-service plans (PFFS), none were offered in Miami-Dade until 2003. PSOs are similar to HMOs, except that they are run by a provider or group of providers. PPOs have provider networks and negotiate rates with providers, but there 
is much less use of medical management through gatekeeping and prior authorization. PFFS plans are indemnity plans (like TM) that were prohibited from having restrictive provider networks and from actively managing care. With the introduction of Medicare's prescription drug benefit, as of 2006, MA plans could be "stand-alone" MA plans, or coupled with a Part D prescription drug plan (MA+PD). The extension of prescription drug coverage through Part D reduced a major advantage of MA plans had over TM, but MA plans often provided more generous drug coverage than was available through Part D plans in TM. MA plans also continued to differentiate themselves from TM through provision of disease management, care coordination and preventive care, as well as continuing to obviate the need to purchase a supplementary insurance (i.e. Medigap) policy. Many MA plans became even more affordable, as they took advantage of new permission to subsidize a beneficiary's Part B premium, thereby reducing a beneficiary's out-of-pocket obligations further.

Table 1 shows the choices by type of plan available to the elderly in Miami-Dade from 2003-2008. ${ }^{4}$ These include both stand-alone MA plans and MA+PD. It is clear that both the number and diversity of MA plans available to beneficiaries grew between 2003 and 2008 . There was relatively steady growth in the overall number of plans each year starting in 2003 until plan choices more than doubled between 2007 and 2008. For the first few years of this period HMOs were the dominant plans offered, and they continue to be the most common type of plan available. PPOs and PSOs began to appear in the market in 2005, but it was the emergence of PFFS plans that really changed the landscape of the choice set in 2007 and 2008. In particular, while PPOs and PSOs were like HMOs with restrictive physician networks (PPOs were somewhat less restrictive), PFFS, with its lack of network restrictions, offered a private TM-like option (often with more generous coverage terms).

\footnotetext{
${ }^{4}$ We excluded all MA plans that are cost-based, Medical Savings Accounts, and all plans associated with an employer/retiree groups.
} 
The diversity in choices available across MA plan offerings and TM is evident in the sideby-side comparison of covered benefits and expected costs in Miami-Dade in 2007 (Table 2). ${ }^{5}$ MA premiums and out-of-pocket costs need to be considered against what beneficiaries must pay in TM for comparable coverage. In order to have TM coverage be equivalent with what is offered in a typical MA plan that includes a Part D prescription drug plan, the beneficiary needs to buy Part D coverage and a supplemental Medigap plan. ${ }^{6}$ Table 2 presents data on the average beneficiary-paid monthly premium and expected out-of-pocket costs (OOPC) in each MA plan and in TM with supplemental coverage through Medigap Plan C. Medigap Plan C is one of the two most popular Medigap policies and it covers nearly all of the cost-sharing requirements in TM (MedPAC 2012). The estimates in Table 2 are an average of premium and OOPC estimates for beneficiaries by age, gender and self-reported health status in plans of each type. ${ }^{7}$ The expected OOPC of MA plans, in particular HMOs, are considerably lower than that in TM. In addition, all MA plans offered some additional benefits over those provided through the TM option, and some HMOs and PSOs offered prescription drug coverage that covered the gap ("the doughnut hole") in the Part D benefit.

The historically high MA penetration in Miami since the mid-1990s suggests that Medicare beneficiaries in Miami have high levels of "taste" for managed care (i.e. a willingness

\footnotetext{
5 This diversity in plan benefits and expected out-of-pocket costs across plans and between MA and TM is similar in the latter part of the study period (2006-2008). For ease of exposition we present data on one year, the mid-point, here.

${ }^{6}$ This is assuming the beneficiary does not have supplemental insurance through a prior employer (30 percent of beneficiaries) nor is she eligible for Medicaid (18 percent).

${ }^{7}$ A description of how these data are calculated is in the data section below.
} 
to accept the restrictions of managed care in exchange for more benefits and cost-savings). ${ }^{8}$ By 2007, however, beneficiaries no longer had to forgo the freedom to choose their physician in order to get the benefits of being in an MA plan, because PFFS plans offer similar added benefits and lower costs without requiring such sacrifices. It is thus evident that the choices among MA plans facing Miami-Dade beneficiaries in 2008 were dramatically different than in 2003 or earlier, that MA offered a much richer benefit at lower cost than TM, and that many more Medicare beneficiaries, even some of those with lower "tastes" for managed care, would be potentially better off in MA than in TM. We now turn to examine empirically patterns of demand for MA in Miami-Dade over the mid-2000s.

\section{Data and Methods}

Data

We obtained data on the entire population of elderly (age 65+) Medicare beneficiaries in Miami-Dade County for the years 2003-2008 from the Centers for Medicare and Medicaid services (CMS). We excluded beneficiaries who became eligible for Medicare due to disability, those dually eligible for Medicaid, the long-term institutionalized, and those enrolled with an insurer outside of Miami-Dade. We analyzed 1,028,772 elderly person-year observations, or about 171,000 beneficiaries per year.

The data include information on beneficiary date of birth, gender, race (non-white vs white $)^{9}$, zip code of residence, whether enrolled in MA and TM in each month, and for those in MA, the year of first enrollment in an MA plan. We also obtained previously determined

\footnotetext{
${ }^{8}$ Indeed, national survey results have found that relative to enrollees in TM, enrollees in MA plans are the most likely to report being willing to forgo choice of provider in order to spend less out-of-pocket for their care (Tu 2005), a not-so-surprising finding given that MA enrollment is voluntary.

${ }^{9}$ Due to data limitations we are unable to control separately for ethnicity.
} 
estimates of the out-of-pocket costs (OOPC), including premiums, associated with each MA plan option in Miami-Dade. The Centers for Medicare and Medicaid Services (CMS) calculated these estimates by taking medical utilization data for a standard population of Medicare beneficiaries and applying the coverage and cost-sharing rules specific to each MA plan to these utilization data to determine the average monthly out-of-pocket costs expected for a beneficiary enrolling in that plan. ${ }^{10}$ These calculations were conducted separately for five selfreported health status groups and six age groups.

Generally, insurers contract with Medicare to offer a specific type of plan (i.e. HMO, PPO, or PFFS) in a county but often offer multiple plans with different names and variable benefits under each contract. Our data include contract-level (but not plan-level) enrollment in MA in Miami-Dade county. Thus, for each age group in Miami-Dade in given year, we averaged OOPC estimates for the five health status groups within plans, and then averaged the OOPC plan estimates for all plans under a given MA contract. We applied Miami-Dade contract-level enrollment data to calculate an enrollment-weighted average OOPC of being in MA in MiamiDade for each age group and year, and we assigned these averages to beneficiaries in our sample based on their age and year. Expected monthly out-of-pocket costs for those in traditional Medicare with a supplemental Medigap Plan C policy coverage were similarly estimated based on the uniform benefits and premiums of traditional Medicare and Floridaspecific supplemental benefits and premiums of Medigap Plan C. As we did for MA, we averaged the estimates across health status groups to come up with single estimate for TM for each age group and year.

\section{Methods}

\footnotetext{
${ }^{10}$ The standard population was a two-year sample of TM-enrolled respondents to the Medicare Current Beneficiary Survey. This estimate assumes that the quantity of services consumed does not vary with the differing cost sharing rules across the MA plans.
} 
We analyzed the demand for MA by beneficiaries over our study period 2003-08. We term beneficiaries who enroll in MA within their first twelve months of eligibility for Medicare and remain continuously enrolled in MA as "incident" enrollees and members of the "incident cohort." Members of this group enrolled in MA at a time when they were forced to make an active choice between TM and MA. Beneficiaries who choose to switch into MA at any point after their first year in the Medicare program, or those who at some point in their history in the Medicare program have a spell during which they are enrolled in TM, are referred to as "non-incident enrollees." At the time when they chose to switch into MA, these enrollees faced a status quo default or an option to make a passive choice.

We estimated logistic regression models to examine the impact of traditional factors that affect demand for health insurance (personal characteristics and prices), and of two contextual factors: when a beneficiary enrolled in MA and a beneficiary's tenure in the Medicare program. The standard economic model of demand does not recognize the difference between an active choice and a default situation in affecting demand. Including measures of these factors in the models allows us to understand whether these latter factors exert an impact on demand for MA plans and if so how.

The dependent variable in these models is binary indicating whether a beneficiary is enrolled in MA (1=yes). Independent variables in our base specification include whether a beneficiary is in her first year of eligibility for Medicare (because we restrict our sample to those eligible for Medicare because of old age, beneficiaries in their first year of eligibility are all age 65), whether a beneficiary is in the incident cohort (i.e. she joined MA when she first became eligible for Medicare and has been continuously enrolled in a MA plan since that time), and whether she was enrolled in MA in the previous year. We also included variables that a priori we thought would affect beneficiary transitions into MA, including beneficiary race, gender, and zip code, the latter being a proxy for income and ethnicity. We also control for the relative generosity of MA through a measure of relative price for MA versus TM, which is defined based 
on the average expected OOPC of enrollment in MA in Miami-Dade and enrollment in TM with supplemental Medigap Plan C in Miami-Dade that we calculated for each of our age groups, and is equal to (average expected OOPC in TM with Medigap Plan C) - (average expected OOPC in MA).

We study the effect of inertia in demand for MA by including indicators for the year in which a beneficiary turned 65 (and first gained eligibility for Medicare), which we term their "cohort year."11 Negative coefficients on the cohort year variables would indicate beneficiaries who have been in the Medicare program longer (i.e., members of any of the cohort years 19702007) are less likely to switch into the MA program than are members of the 2008 cohort, suggesting status quo bias.

The sample for the logistic regression models includes data from the years 2004, 2005, 2007 and 2008. Because of missing data on expected MA plan costs we exclude data from 2006 from this analysis. Models include year fixed effects for the period spanned by our data, and standard errors are clustered at the beneficiary level. For ease of interpretation, we report our results in terms of predicted values based on the logistic regression models varying the indicator for whether a beneficiary is in their first year in Medicare, a member of the incident cohort and enrolled in MA in the previous year and as marginal effects with p-values.

\section{Results}

\section{Descriptive results}

From 2003-2008 approximately 55\% of our study population was enrolled in an MA plan, almost three times the rate of average penetration observed across the US (Table 1). Table 3

\footnotetext{
${ }^{11}$ Because Medicare eligibility rules deem all individuals in our sample first eligible for Medicare when they turn 65, age and cohort are perfectly collinear and we are unable to separately estimate the effect of beneficiary age on transitions into MA in this analysis.
} 
describes the characteristics of Miami-Dade enrollees in TM and MA. MA enrollees are more likely to be non-white and in their late-60s and 70s than are enrollees in TM. Within MiamiDade there is considerable variation in elderly demographics and MA penetration by neighborhood (Table 4).

There is a consistent and high rate of take-up of MA among the incident cohort over the entire study period; approximately $40 \%$ of the elderly who are newly eligible for Medicare elect to enroll in MA while the rest enter TM (Table 5). Among the non-incident cohort, which includes all beneficiaries who were enrolled in TM in the previous year, approximately 5\% switch into MA from TM in each of the study years. Even though the percentage of nonincident enrollees going into TM is much smaller, because the pool of these beneficiaries (relative to the incident cohort) is quite large, slightly more than half of new MA enrollees each year are from the incident cohort each year and the remainder switch in from TM.

The bottom row in Table 5 reports on the composition of all MA enrollees in terms of whether beneficiaries joined MA during their incident year versus any other year. These results provide an indication of whether transition patterns observed in 2003-08 are consistent with transitions into MA in earlier periods. In 2003, 35\% of all Miami-Dade MA enrollees had joined the program during their first year of Medicare eligibility, and by 2008 this proportion increased to $44 \%$. Thus, by the end of our study period, a greater proportion of MA enrollees are incident cohort enrollees, suggesting that being a member of the incident cohort is incrementally much more important to MA take-up than it was in earlier periods.

\section{Regression Results}

Logistic regression models analyzing the probability that a beneficiary is enrolled in MA (vs TM) give an indication of the contribution of first joining the Medicare program, relative to other characteristics, on transitions into MA. These results suggest that the first year of eligibility for Medicare is an important decision point for beneficiaries. Table 6 reports the predicted probability, based on our models, that individuals with certain attributes are enrolled in 
an MA plan, and that individuals in their first year of eligibility (age 65) are significantly more likely than those who have been enrolled in Medicare for at least one year to join MA (61.4\% vs. $57.5 \%, p<0.001)$

We find evidence of status quo bias in MA transitions. The most important factor in explaining whether a beneficiary is in MA in the current year is whether or not they were in MA in the previous year. Table 6 shows that beneficiaries in MA in the previous year are seven times as likely to be in MA in the next year in comparison to enrollees in TM in the previous year (98.0\% vs. $14.7 \%, p<0.001)$, suggesting that beneficiaries who enroll in MA stay in the program over time. Estimates on the cohort year control variables (Table 7) show that the probability of being in MA (versus TM) is monotonically decreasing with each year that a beneficiary is in Medicare, suggesting that inertia also exists in transitions from TM to MA, and that this inertia is time dependent as beneficiaries enrollment in TM becomes increasingly "sticky" with time.

We also observe that individuals who joined MA during their incident year are significantly more likely than those in the non-incident cohort to be enrolled in MA (68.3\% vs. $56.8 \%, p<0.001)$. This finding illustrates that incident cohort enrollees have a disproportionate role in the composition of MA enrollees, which is, in effect, the long-term impact of the combination of the facts that beneficiaries are more likely to join in their first year and that there is substantial inertia in the market.

Implications for Enrollees

MA plans offer additional benefits over TM including vision coverage, hearing coverage, and some additional drug coverage; however the primary additional benefits provided by MA over TM are lower expected out-of-pocket costs for an equivalent benefit. In the case of PFFS plans in 2007 and 2008, this benefit is available without having to sacrifice access to physicians or to be in a plan where care is managed. We estimate the average annual out-of-pocket cost for all elderly beneficiaries of being in TM (plus Medigap Part C), in an MA-HMO, in an MA- 
PFFS plan, or in any MA plan in 2007 and $2008 .{ }^{12}$ We then calculate the beneficiary's annual savings from being in MA versus TM in 2007 and 2008 by type of MA plan as the difference between the average annual out-of-pocket cost between TM and the relevant MA option. Table 8 shows that an enrollee could save around $\$ 3000$ annually in MA in those years. In 2011 , the median household income for householders age $65+$ in Miami-Dade county was $\$ 24,108$; thus estimated savings from MA represents more than $10 \%$ of average annual income. Savings would be greater, between to $\$ 3500$ and $\$ 4000$, if a beneficiary chose to enroll in an HMO and somewhat less, between $\$ 1300$ and $\$ 1600$ if they enrolled in a PFFS plan. ${ }^{13}$

\section{Discussion}

Gaining eligibility for Medicare, most commonly when one turns age 65, marks a key decision point for beneficiaries as this is when elderly beneficiaries first enroll in Medicare. At that time new beneficiaries consider whether TM or MA is better for them. While TM is given special emphasis in enrollment materials (page placement and separation from other plans) new beneficiaries are asked to make an active decision about joining TM or MA. After this point, switching into MA not only requires a beneficiary to compare the option of MA versus TM but also to overcome the default of remaining in TM. Our analysis suggests that turning 65 is the key transition point for MA, as we find that being in one's incident year of eligibility for Medicare is very important to take-up of MA. Patterns of transitions into MA from TM (and vice versa) following this point suggest significant status quo bias in take-up of MA, and that this 'stickiness' increases with a beneficiary's tenure in Medicare. Because of the timing of when they aged into Medicare, the consequence of these patterns in demand is that those

\footnotetext{
12 Average annual out-of-pocket cost in any MA plan in one year is the average expected out of pocket cost in all MA plans across all ages that year, multiplied by twelve. The average annual out-of-pocket cost in an MA-HMO (MA-PFFS) plan in one year is the equivalent calculation for MA-HMO (MA-PFFS) plans only. The average annual out-of-pocket cost in TM plus Medigap Plan C is the average expected out-of-pocket costs in TM plus Plan C across all ages, multiplied by twelve.

${ }^{13}$ Source: US census bureau, American Community Survey, Table B19049
} 
beneficiaries turning 65 in 2003-08 disproportionately benefited from entering MA, while those already in Medicare were most likely to be the ones "leaving money on the table."

The reasons for this pattern of behavior are not completely understood. For the incident cohort, elements of the Medicare entry process (e.g. filling out paperwork, engaging with the Social Security office, choosing a Part C plan or, if in TM, a Part D and/or Medigap plan) make Medicare entry an active choice regardless of the Medicare policy environment or the complexity of the Medicare plan choice set. For the non-incident cohort however, in any year a decision to switch into MA requires overcoming a "default" option of staying in TM, evaluating MA options and deciding to switch plans. The differences between making an active and a passive choice is likely driving the strong incident effect that we observe in our data. Other studies of health insurance choice have found that as choice sets become larger and more complex not only are the search costs that are required to select the right plan higher, but the complexity itself may make beneficiaries more susceptible to inertia and defaults (Frank and Lamiraud 2009). Indeed, throughout our study period, the MA choice set in Miami-Dade county becomes larger and more complex and we find that being a member of the incident cohort is increasingly important to take-up of MA, suggesting that as the choice environment becomes more complex beneficiaries who have to overcome a passive choice to enroll in MA are less likely to do so.

Health plans also have an incentive to attract younger enrollees and take active steps to discourage older and sicker enrollees from switching into MA so as to avoid adverse selection. This plan-level incentive may also account for some of the patterns of demand for MA and the incident effect that we observe in Miami-Dade, and we are unable to disentangle these effects in our data. However, studies of the impact on changes in Medicare plan payment (i.e., the implementation of risk-adjustment) aimed and reducing risk selection over this same time period find evidence of reductions in favorable selection into MA (McWilliams et al 2012), suggesting 
that plan-level efforts to achieve favorable selection are not solely responsible for our observed incident effect.

The incident effect and the status quo bias among beneficiaries could also undermine the efficiency of the MA market overall. Plans observe patterns of beneficiary enrollment and demand, and these enrollment patterns give plans the incentive to compete only for the youngest elderly. They can do so by offering services and access to providers in which that the younger elderly are most interested. In contrast, plans have a type of market power over older adults; plans can offer less attractive combinations of premiums, coverage and services quality and still retain the oldest enrollees due to the inertia. To the extent that these unfavorable combinations of premiums and benefits are least acceptable to those beneficiaries who are sicker and expect to use more care and serve to push them to switch back into TM, these market conditions may also exacerbate the adverse selection that has already been observed in MA markets (Riley and Zarabozo 2006-2007; Newhouse et al 2012).

This paper has a few important limitations. First, because the analysis is focused only on Miami-Dade county these findings may not generalize fully to other parts of the US that are different from Miami along characteristics not included in our data (and therefore unable to be controlled for in our models), in particular to areas where the market for MA is significantly different or where beneficiaries have less experience with and "taste" for managed care. However, to the extent that the MA program continues its current growth in terms of the number of plans offered and the number of beneficiaries enrolled in the program, more markets may begin to resemble Miami-Dade and these findings may become more relevant. Second, data limitations prevent us from including several individual-level controls in the models, including health status and ethnicity. Health status is known to be correlated with demand for insurance, in particular managed care, and, aside from other evidence that favorable selection into MA is decreasing over this period, we are unable to assess the impact of health status on MA take-up in this study. In Miami-Dade, the implication of omitting ethnicity is that we are unable to assess 
whether the patterns in demand for MA that we observe varied for beneficiaries who identify as Hispanic and white versus non-Hispanic and white.

Finally, because of the collinearity between age and cohort we cannot control separately for age in the models. The implication of being unable to separately measure age is that our estimates of the effect of cohort may include any separate effect of declining enrollment in MA with age, and represent an upper bound (in absolute value). Ideally further research can work to disentangle the contributions of cohort and age on beneficiary enrollment in MA.

Over the period from 2006-2009, Medicare is estimated to have over-paid plans (relative to what it would have cost to insure MA enrollees in TM) by 12-14\% annually (MedPAC 2009b). However, passage of the Affordable Care Act of 2010 (ACA) includes several provisions that will decrease MA plan payments going forward. Understanding beneficiary choice of MA becomes increasingly important in an environment of tighter public budgets. With better information about the drivers of beneficiary choice, including the effects of health plan search frictions such as inertia and defaults, policymakers can better assess the impact of different payment environments and implement policy that improves the efficiency of the MA market whereby MA plans have incentives to compete for all beneficiaries and not just the newest. For example, policy interventions and communication strategies that reduce complexity in the choice environment so as to address choice overload and the ability to comparison shop could lead to greater take-up of MA by incumbent beneficiaries. Our results suggest however that these policies could be more effective if paired with interventions that make beneficiaries more engaged in the annual plan renewal and open enrollment process, for example through policy "nudges" that make a beneficiary's continued enrollment in Medicare an active as opposed to passive process. Such policy has the potential to make non-incident beneficiaries better off, if by transitioning into MA they are able to take advantage of a generous benefit at lower out-ofpocket cost, such as that offered in Miami-Dade in 2007 and 2008. 


\section{References}

Abaluck, Jason, and Jonathan Gruber. 2011. "Choice Inconsistencies among the Elderly: Evidence from Plan Choice in the Medicare Part D Program." American Economic Review, 101(4): 1180-1210.

Baicker K, Congdon WJ, and Mullainathan S. (2012) "Health Insurance Coverage and Take-Up: Lessons from Behavioral Economics," The Milbank Quarterly 90(1): 107-134

Beshears, J, Choi JJ, Laibson D, and Madrian BC. (2008) "How are preferences revealed?" Journal of Public Economics 92 (8-9): 1787-1794.

Frank RG and K Lamiraud (2009). "Choice, price competition and complexity in markets for health insurance," Journal of Economic Behavior and Organization. 71:550-562

Hanoch Y and Rice, T. (2006) "Can Limiting Choice Increase Social Welfare? The Elderly and Health Insurance." Milbank Quarterly 84(1): 37-73.

Hurley RE, Grossman JM and Strunj BC. "Medicare Contracting Risk / Medicare Risk Contracting: A Life-Cycle View from Twelve Markets." Health Services Research 38(1) 2003: 395-417.

Ginsburg S, Kates J, Kohn LT, and Williams MD. "Health System Change in Miami, Fla." Miami Case Study, Center for Studying Health System Change, 1997. Available online at: http://www.hschange.com/CONTENT/219/ (Accessed November 19, 2012). 
Gold, M. (2009) "Medicare's Private Plans: A Report Card on Medicare Advantage," Health Affairs, 28(1): w41-w54. (Published online November 24, 2008; 10.1377/hlthaff.28.1.w41)

Gold M, Jacobson G, Damico A, and Neuman T. (2012) "Medicare Advantage 2012 Data Spotlight: Enrollment Market Update." Kaiser Family Foundation. Available online at http://www.kff.org/medicare/upload/8323.pdf (Accessed February 4, 2013).

Goldstein DG, EJ Johnson, A Herrmann and M Heitman (2008), "Nudge Your Customers Toward Better Choices" Harvard Business Review (December)

Kahneman, D., and Tversky, A. (1982) "The Psychology of Preference," Scientific American 246:160-173

Kempf A and Ruenzi S. (2006) "Status Quo Bias and the Number of Alternatives: An Empirical Illustration from the Mutual Fund Industry." Journal of Behavioral Finance 7(4): 204-213

Madrian BC and Shea DF (2001) The power of suggestion: Inertia in 401(k) participation and savings behavior. Quarterly Journal of Economics 116:1149-1187.

Mays GP, Trude S, Casalino LP, Lichiello P, Short AC and Benoit A. "Hospitals Profit from Aggressive Negotiations: Miami, Fla Summer 2001" Center for Studying Health System Change Community Report, Third Visit 2000-01. Available online at: http://www.hschange.com/CONTENT/333/ (Accessed November 19, 2012)

McGuire TG, Newhouse JP, Sinaiko AD. (2011) "An Economic History of Medicare Part C." Milbank Quarterly 89(2): 289-332. 
McWilliams JM, Afendulis CC, McGuire TG and Landon BE. (2011) "Complex Medicare Advantage Choices May Overwhelm Seniors - Especially Those with Impaired Decision Making." Health Affairs 30(9): 1786-1794.

McWilliams JM, Hsu J, Newhouse JP. (2012) "New Risk-Adjustment System Was Associated with Reduced Favorable Selection in Medicare Advantage," Health Affairs 31(12): 2630-2640.

Medicare Payment Advisory Commission (2000), "Report to the Congress: Improving Risk Adjustment in Medicare." Washington, DC: Medicare Payment Advisory Commission.

Medicare Payment Advisory Commission (2007), "Report to Congress: Medicare Payment Policy," Washington, DC: Medicare Payment Advisory Commission.

Medicare Payment Advisory Commission (2009a), "Report to Congress: Medicare Payment Policy," Washington, DC: Medicare Payment Advisory Commission.

Medicare Payment Advisory Commission (2009b), "Report to the Congress: Improving Incentives in the Medicare Program," Washington, DC: Medicare Payment Advisory Commission.

Medicare Payment Advisory Commission (2011), "Report to Congress: Medicare Payment Policy," Washington, DC: Medicare Payment Advisory Commission.

Medicare Payment Advisory Commission (2012), "Report to Congress: Medicare and the Health Care Delivery System," Washington, DC: Medicare Payment Advisory Commission. 
Neuman P and Cubanski J. (2009) "Medicare Part D Update - Lessons Learned and Unfinished Business," NEJM 361(4): 406-414

Newhouse JP, Price M, Huang J, McWilliams JM, Hsu J. (2012) "Steps To Reduce Favorable Risk Selection In Medicare Advantage Largely Succeeded, Boding Well For Health Insurance Exchanges," Health Affairs, 31(12):2618-2628

Norwalk, Leslie, CMS Acting Administrator. Testimony before House Ways and Means Committee. March 21, 2007.

Physician Payment Review Commission (1996), Annual Report to Congress, 1996, Washington, DC: Physician Payment Review Commission.

Riley, G and Zarabozo, C. 2006-2007 "Trends in the Health Status of Medicare Risk Contract Enrollees," Health Care Financing Review 28(2): 81-95.

Samuelson, W, and Zeckhauser, R. (1988) "Status Quo Bias in Decision Making" Journal of Risk and Uncertainty, 1:7-59.

Sinaiko AD and Hirth RA. (2011) "Consumers, Health Insurance and Dominated Choices." Journal of Health Economics 30:450-457.

Strombom, B.A., Buchmueller, T.C., Feldstein, P.J., 2002. Switching costs, price sensitivity and health plan choice. Journal of Health Economics 21, 89-116. 
Tversky, A, and Kahneman, D. (1991) “Loss Aversion in Riskless Choice: A ReferenceDependent Model" The Quarterly Journal of Economics, 106(4) :1039-1061

Tu, HT. "Medicare Seniors Much Less Willing to Limit Physician Hospital Choice for Lower Costs," Issue Brief No. 96 Center for Studying Health System Change (June 2005). Available online at: http://www.hschange.com/CONTENT/744/744.pdf (Accessed November 19, 2012). 
Table 1. Number of Medicare Advantage Plan choices and MA penetration in Miami-Dade County

\begin{tabular}{|c|c|c|c|c|c|c|c|}
\hline & \multicolumn{5}{|c|}{ Number of plans in Miami-Dade: } & \multicolumn{2}{|c|}{ MA penetration } \\
\hline & All MA plans & HMO & PPO & PFFS & PSO & Miami-Dade & National \\
\hline 2003 & 21 & 20 & 0 & 0 & 1 & $58 \%$ & $15 \%$ \\
\hline 2004 & 21 & 20 & 0 & 0 & 1 & $58 \%$ & $15 \%$ \\
\hline 2005 & 44 & 35 & 4 & 0 & 5 & $57 \%$ & $15 \%$ \\
\hline 2006 & 47 & 33 & 9 & 1 & 4 & $57 \%$ & $17 \%$ \\
\hline 2007 & 51 & 32 & 6 & 8 & 5 & $58 \%$ & $21 \%$ \\
\hline 2008 & 123 & 77 & 9 & 32 & 5 & $57 \%$ & $23 \%$ \\
\hline
\end{tabular}

Source for number of plans: Publicly available data from the Centers for Medicare and Medicaid Services

Notes: MA - Medicare Advantage, HMO - Health Maintenance Organization, PPO - Preferred Provider Organization, PFFS - Private Fee For Service, PSO - Provider Sponsored Organization

Source for penetration rates: Authors analysis of Medicare enrollment data

Sample includes Medicare beneficiaries age 65+, who gained eligibility for Medicare because of old age, and not dual eligible 
Table 2. Comparison of Medicare Advantage plan benefits, Miami-Dade County 2007

\begin{tabular}{lccccc} 
& All MA plans & HMO & PPO & PFFS & TM + Plan C \\
\hline Avg monthly Premium & 88.05 & 88.01 & 102.56 & 73.9 & 317.57 \\
Avg monthly OOPC & 182.49 & 181.27 & 329.55 & 256.73 & 409.07 \\
\# Carriers & 20 & 15 & 4 & 4 & 1 \\
Offer Vision Coverage & $73 \%$ & $81 \%$ & $67 \%$ & $25 \%$ & No \\
Offer Hearing Coverage & $39 \%$ & $38 \%$ & $33 \%$ & $13 \%$ & No \\
Offer Dental Coverage & $75 \%$ & $81 \%$ & $83 \%$ & $25 \%$ & No \\
Offer Drug Coverage & $86 \%$ & $91 \%$ & $67 \%$ & $75 \%$ & Separate \\
Avg.Physician Network Size & 1,779 & 1,292 & 4,667 & NA & NA \\
Offer Drug Gap Coverage & $41 \%$ & $44 \%$ & $0 \%$ & $0 \%$ & $0 \%$ \\
\hline Source: Publicly available
\end{tabular}

Source: Publicly available data from the Centers for Medicare and Medicaid Services

Notes: MA - Medicare Advantage, HMO - Health Maintenance Organization, PPO - Preferred

Provider Organization, PFFS - Private Fee For Service, TM + Plan C- Traditional Medicare together with Medigap Plan C 
Table 3. Study population, Miami-Dade county, 2007

\begin{tabular}{|c|c|c|c|}
\hline & $\mathrm{TM}$ & $\mathrm{MA}$ & $p$-value \\
\hline enrollees & 68,931 & 97,716 & \\
\hline penetration & $41 \%$ & $59 \%$ & \\
\hline Female & $53.6 \%$ & $53.2 \%$ & 0.10 \\
\hline \multicolumn{4}{|l|}{ Age } \\
\hline Age 65 & $9.7 \%$ & $4.3 \%$ & $<0.001$ \\
\hline Age 66-69 & $25.6 \%$ & $22.2 \%$ & $<0.001$ \\
\hline Age $70-74$ & $19.7 \%$ & $27.4 \%$ & $<0.001$ \\
\hline Age 75-79 & $17.2 \%$ & $22.5 \%$ & $<0.001$ \\
\hline Age $80-84$ & $14.1 \%$ & $14.1 \%$ & 0.985 \\
\hline Age $85+$ & $13.8 \%$ & $9.5 \%$ & $<0.001$ \\
\hline Non-white & $32.5 \%$ & $21.6 \%$ & $<0.001$ \\
\hline \multicolumn{4}{|c|}{$\begin{array}{l}\text { Source: Author's analysis of Medicare enrollment files } \\
\text { Sample includes Medicare beneficiaries age } 65+, \\
\text { who gained eligibility for Medicare because of old age, } \\
\text { and not dual eligible }\end{array}$} \\
\hline \multicolumn{4}{|c|}{ TM = Traditional Medicare, $\mathrm{MA}=$ Medicare Advantage } \\
\hline
\end{tabular}


Table 5. Descriptive Statistics, elderly in Miami-Dade County by neighborhood, 2006

\begin{tabular}{|c|c|c|c|c|c|c|c|c|c|c|}
\hline \multirow[b]{2}{*}{ neighborhood } & \multicolumn{3}{|c|}{ MA } & \multirow[b]{2}{*}{ black } & \multirow[b]{2}{*}{ Age 65} & \multirow[b]{2}{*}{ Age 66-69 } & \multirow[b]{2}{*}{ Age $70-74$} & \multirow[b]{2}{*}{ Age 75-79 } & \multirow[b]{2}{*}{ Age $80-84$} & \multirow[b]{2}{*}{ Age 85+ } \\
\hline & enrolles & penetration & female & & & & & & & \\
\hline All Dade County & 170440 & $57.5 \%$ & $53.4 \%$ & $11.3 \%$ & $6.5 \%$ & $23.5 \%$ & $23.9 \%$ & $20.4 \%$ & $13.9 \%$ & $11.7 \%$ \\
\hline Coconut Grove & 2883 & $41.0 \%$ & $52.6 \%$ & $10.9 \%$ & $6.2 \%$ & $21.5 \%$ & $23.0 \%$ & $20.6 \%$ & $14.6 \%$ & $14.1 \%$ \\
\hline Coral Gables & 1621 & $25.8 \%$ & $55.3 \%$ & $0.8 \%$ & $5.7 \%$ & $19.9 \%$ & $20.5 \%$ & $21.3 \%$ & $16.7 \%$ & $15.9 \%$ \\
\hline Downtown Miami & 4037 & $42.9 \%$ & $49.1 \%$ & $5.2 \%$ & $6.2 \%$ & $21.4 \%$ & $22.7 \%$ & $19.9 \%$ & $14.0 \%$ & $15.8 \%$ \\
\hline Hialeah & 20660 & $72.5 \%$ & $49.7 \%$ & $2.3 \%$ & $6.9 \%$ & $25.7 \%$ & $26.5 \%$ & $20.9 \%$ & $12.2 \%$ & $7.8 \%$ \\
\hline Hialeah Gardens & 1892 & $72.8 \%$ & $45.7 \%$ & $1.3 \%$ & $9.4 \%$ & $32.9 \%$ & $26.6 \%$ & $18.4 \%$ & $7.8 \%$ & $5.0 \%$ \\
\hline Homestead & 4548 & $54.5 \%$ & $51.0 \%$ & $12.6 \%$ & $7.3 \%$ & $26.4 \%$ & $26.1 \%$ & $19.0 \%$ & $12.2 \%$ & $9.1 \%$ \\
\hline Key Biscayne/Virginia Key & 1449 & $19.9 \%$ & $52.8 \%$ & $0.2 \%$ & $6.6 \%$ & $21.5 \%$ & $21.9 \%$ & $21.5 \%$ & $15.4 \%$ & $13.0 \%$ \\
\hline Miami Beach & 20934 & $35.1 \%$ & $57.3 \%$ & $1.1 \%$ & $4.5 \%$ & $17.0 \%$ & $19.9 \%$ & $21.4 \%$ & $17.7 \%$ & $19.6 \%$ \\
\hline NE Miami & 11425 & $48.6 \%$ & $54.4 \%$ & $18.2 \%$ & $6.7 \%$ & $22.1 \%$ & $21.0 \%$ & $19.7 \%$ & $14.7 \%$ & $15.8 \%$ \\
\hline NW Miami & 24967 & $67.3 \%$ & $52.4 \%$ & $32.1 \%$ & $6.8 \%$ & $24.5 \%$ & $25.2 \%$ & $19.8 \%$ & $13.0 \%$ & $10.7 \%$ \\
\hline Opa-Locka & 5763 & $74.2 \%$ & $52.2 \%$ & $61.0 \%$ & $8.8 \%$ & $29.4 \%$ & $26.5 \%$ & $18.0 \%$ & $10.3 \%$ & $6.9 \%$ \\
\hline SW Miami & 70261 & $59.2 \%$ & $54.2 \%$ & $5.4 \%$ & $6.6 \%$ & $24.2 \%$ & $24.1 \%$ & $20.6 \%$ & $13.9 \%$ & $10.5 \%$ \\
\hline
\end{tabular}

Source: Author's analysis of Medicare enrollment files

Notes:

Sample includes Medicare beneficiaries age 65+, who gained eligibility for Medicare because of old age, and not dual eligible

Coconut Grove includes zip code 33133, Coral Gables 33146, Downtown 33128-33131, Hileah 33010, 33012-33016, Hileah Gardens 33018,

Homestead 33030-33035, Key Biscayne/Virginia Key 33149, Miami Beach 33139-33141, 33154, 33160, 33180, NE Miami 33132, 33137, 33138, 33161,

33162, 33179, 33181, NW Miami 33125-33127, 33136, 33142, 33147, 33150, 33166-33169, 33172, 33178, 33182, Opa-Locka 33054-33056

SW Miami 33134-33135, 33143-33145, 33155-33158, 33165, 33170, 33173-33177, 33183-33187, 33189, 33190, 33193, 33196 
Table 5. Transitions into Medicare Advantage in Miami-Dade County, 2004-2008

\begin{tabular}{|c|c|c|c|c|c|c|c|c|c|c|}
\hline & \multicolumn{2}{|c|}{2004} & \multicolumn{2}{|c|}{2005} & \multicolumn{2}{|c|}{2006} & \multicolumn{2}{|c|}{2007} & \multicolumn{2}{|c|}{2008} \\
\hline & $\mathrm{N}$ & percent & $\mathrm{N}$ & percent & $\mathrm{N}$ & percent & $\mathrm{N}$ & percent & $\mathrm{N}$ & percent \\
\hline \multicolumn{11}{|l|}{ Incident Cohort } \\
\hline Enroll in MA & 4,778 & $42 \%$ & 4,329 & $38 \%$ & 4,271 & $38 \%$ & 4,197 & $38 \%$ & 4,121 & $36 \%$ \\
\hline Enroll in TM & 6,650 & $58 \%$ & 6,922 & $62 \%$ & 6,840 & $62 \%$ & 6,786 & $62 \%$ & 7,452 & $64 \%$ \\
\hline \multicolumn{11}{|c|}{ Non-Incident Cohort (TM in previous year) } \\
\hline Switch to MA & 3,408 & $5 \%$ & 3,220 & $5 \%$ & 4,053 & $6 \%$ & 4,700 & $7 \%$ & 3,576 & $5 \%$ \\
\hline Stay in TM & 61,201 & $95 \%$ & 61,900 & $95 \%$ & 61,683 & $94 \%$ & 61,038 & $93 \%$ & 62,028 & $95 \%$ \\
\hline \multicolumn{11}{|c|}{ Among New MA enrollees } \\
\hline Age 65 & 4,778 & $58 \%$ & 4,329 & $57 \%$ & 4,271 & $51 \%$ & 4,197 & $47 \%$ & 4,121 & $54 \%$ \\
\hline Age $66+$ & 3,408 & $42 \%$ & 3,220 & $43 \%$ & 4,053 & $49 \%$ & 4,700 & $53 \%$ & 3,576 & $46 \%$ \\
\hline \multicolumn{11}{|c|}{ Percentage of all MA enrollees who enrolled in their incident cohort year* } \\
\hline & & $35 \%$ & & $37 \%$ & & $39 \%$ & & $42 \%$ & & $44 \%$ \\
\hline
\end{tabular}

Source: Statistical analysis of Medicare enrollment files, 2003-2008, data from July of each year. Does not include beneficiaries who died during the year.

Sample includes Medicare beneficiaries age 65+, who gained eligibility for Medicare because of old age, and not dual eligible

*incident $=$ joined MA within 12 mos of Medicare 
Table 6. Estimated Probability of Medicare Advantage enrollment, Miami-Dade

\begin{tabular}{lccc}
\hline & Yes & No & p-value \\
\hline & & & \\
Incident cohort member & $68.3 \%$ & $56.8 \%$ & $<0.001$ \\
In MA last year & $98.0 \%$ & $14.7 \%$ & $<0.001$ \\
First year of eligibiliy for Medicare & $61.4 \%$ & $57.5 \%$ & $<0.001$ \\
\hline
\end{tabular}

Source: Statistical analysis of Medicare enrollment files, 2004-05, 2007-08

Notes: Predicted probabilities based on logistic regression models that controlled for

beneficiary gender, race, zip code, cohort year, the relative generosity of MA versus TM, and year fixed effects 
Table 7. Factors associated with transitions into Medicare Advantage, Miami-Dade county 2004-05 \& 2007-08 Logistic regression, marginal effects

\begin{tabular}{|c|c|c|c|c|c|c|}
\hline \multicolumn{7}{|c|}{ Dep Var: Enrolled in any MA plan (1=yes) } \\
\hline & $m$ effect & s.e. & p-value & $m$ effect & s.e. & $\mathrm{p}$-value \\
\hline incident cohort & 0.12264 & 0.00146 & 0.000 & 0.1144495 & 0.0023601 & 0.00 \\
\hline in MA in previous year & 0.84633 & 0.00107 & 0.000 & 0.8328872 & 0.0041946 & 0.00 \\
\hline male & -0.00137 & 0.00049 & 0.005 & -0.0022975 & 0.0004848 & 0.01 \\
\hline nonwhite & 0.02001 & 0.00060 & 0.000 & 0.0133324 & 0.0006574 & 0.00 \\
\hline avearge relative oopc & 0.00006 & 0.00004 & 0.152 & 0.0000577 & $0.0000417^{r}$ & 0.166 \\
\hline first year in Medicare & 0.04085 & 0.00142 & 0.000 & 0.0387487 & 0.0015963 & 0.000 \\
\hline year fixed effects & YES & & & YES & & \\
\hline zip code dummies & NO & & & YES & & \\
\hline \multicolumn{7}{|l|}{ cohort_yr } \\
\hline 1969 & -0.08996 & 0.01321 & 0.000 & -0.0827356 & 0.0132042 & 0.000 \\
\hline 1970 & -0.10651 & 0.01029 & 0.000 & -0.097587 & 0.0100918 & 0.000 \\
\hline 1971 & -0.10803 & 0.01003 & 0.000 & -0.0984077 & 0.0101523 & 0.000 \\
\hline 1972 & -0.10139 & 0.00735 & 0.000 & -0.0941466 & 0.0076283 & 0.000 \\
\hline 1973 & -0.10473 & 0.00651 & 0.000 & -0.0954583 & 0.0065446 & 0.000 \\
\hline 1974 & -0.09337 & 0.00536 & 0.000 & -0.0850793 & 0.0056312 & 0.000 \\
\hline 1975 & -0.08948 & 0.00550 & 0.000 & -0.0803971 & 0.0057183 & 0.000 \\
\hline 1976 & -0.08203 & 0.00522 & 0.000 & -0.0728955 & 0.0054261 & 0.000 \\
\hline 1977 & -0.08562 & 0.00481 & 0.000 & -0.0769208 & 0.0050091 & 0.000 \\
\hline 1978 & -0.08573 & 0.00473 & 0.000 & -0.0780398 & 0.0049073 & 0.000 \\
\hline 1979 & -0.08639 & 0.00463 & 0.000 & -0.0787828 & 0.0048178 & 0.000 \\
\hline 1980 & -0.08179 & 0.00459 & 0.000 & -0.0738325 & 0.0047439 & 0.000 \\
\hline 1981 & -0.08280 & 0.00453 & 0.000 & -0.0751505 & 0.0046715 & 0.000 \\
\hline 1982 & -0.08109 & 0.00447 & 0.000 & -0.0739244 & 0.0045877 & 0.000 \\
\hline 1983 & -0.08355 & 0.00439 & 0.000 & -0.075539 & 0.0045305 & 0.000 \\
\hline 1984 & -0.08255 & 0.00438 & 0.000 & -0.0753068 & 0.004519 & 0.000 \\
\hline 1985 & -0.08187 & 0.00458 & 0.000 & -0.0745459 & 0.0047048 & 0.000 \\
\hline 1986 & -0.08461 & 0.00462 & 0.000 & -0.0774037 & 0.0047495 & 0.000 \\
\hline 1987 & -0.08280 & 0.00462 & 0.000 & -0.0753429 & 0.004729 & 0.000 \\
\hline 1988 & -0.08133 & 0.00474 & 0.000 & -0.0739717 & 0.0048533 & 0.000 \\
\hline 1989 & -0.08037 & 0.00474 & 0.000 & -0.0733307 & 0.0048313 & 0.000 \\
\hline 1990 & -0.07747 & 0.00459 & 0.000 & -0.0706733 & 0.0046775 & 0.000 \\
\hline 1991 & -0.08054 & 0.00448 & 0.000 & -0.0740824 & 0.0045874 & 0.000 \\
\hline 1992 & -0.08089 & 0.00448 & 0.000 & -0.0742782 & 0.0045859 & 0.000 \\
\hline 1993 & -0.07881 & 0.00441 & 0.000 & -0.0721624 & 0.0045061 & 0.000 \\
\hline 1994 & -0.07837 & 0.00439 & 0.000 & -0.0715528 & 0.0044883 & 0.000 \\
\hline 1995 & -0.07830 & 0.00428 & 0.000 & -0.071964 & 0.0043917 & 0.000 \\
\hline 1996 & -0.07820 & 0.00421 & 0.000 & -0.0722838 & 0.0043034 & 0.000 \\
\hline 1997 & -0.07576 & 0.00427 & 0.000 & -0.0694965 & 0.0043505 & 0.000 \\
\hline 1998 & -0.07654 & 0.00406 & 0.000 & -0.0708163 & 0.0041627 & 0.000 \\
\hline 1999 & -0.07341 & 0.00381 & 0.000 & -0.0680762 & 0.0039188 & 0.000 \\
\hline 2000 & -0.07167 & 0.00366 & 0.000 & -0.0664858 & 0.0037731 & 0.000 \\
\hline 2001 & -0.06466 & 0.00345 & 0.000 & -0.059494 & 0.0035231 & 0.000 \\
\hline 2002 & -0.05486 & 0.00340 & 0.000 & -0.0511805 & 0.0034261 & 0.000 \\
\hline 2003 & -0.04365 & 0.00326 & 0.000 & -0.040655 & 0.0032177 & 0.000 \\
\hline 2004 & -0.03409 & 0.00256 & 0.000 & -0.0324626 & 0.0025249 & 0.000 \\
\hline 2005 & -0.03019 & 0.00240 & 0.000 & -0.0284889 & 0.002361 & 0.000 \\
\hline 2006 & -0.01371 & 0.00315 & 0.000 & -0.0130796 & 0.0029838 & 0.000 \\
\hline 2007 & -0.01223 & 0.00223 & 0.000 & -0.0115042 & 0.0021149 & 0.000 \\
\hline sample size & 672,728 & & & 672,728 & & \\
\hline
\end{tabular}


Table 8. Annual difference in beneficiary expected out-of-pocket cost in Traditional Medicare (TM) versus Medicare Advantage (MA)

\begin{tabular}{ccccc} 
& \multicolumn{2}{c}{2007} & \multicolumn{2}{c}{2008} \\
\hline TM - MA & $\$$ & 2,887 & $\$$ & 3,182 \\
TM - HMO & $\$$ & 3,428 & $\$$ & 4,043 \\
TM - PFFS & $\$$ & 1,300 & $\$$ & 1,629 \\
\hline
\end{tabular}

Source: Authors analysis of Medicare plan data

Notes: HMO - Health Maintenance Organization,

PFFS - Private Fee For Service 